University of Wollongong

Research Online

Faculty of Engineering - Papers (Archive)

Faculty of Engineering and Information

Sciences

2008

\title{
Urethral alarm probe for permanent prostate implants
}

\author{
Dean Cutajar \\ University of Wollongong, deanc@uow.edu.au \\ Michael L. Lerch \\ University of Wollongong, mlerch@uow.edu.au \\ George J. Takacs \\ University of Wollongong, gjt@uow.edu.au \\ Bong Soo Lee \\ Konkuk University \\ Y Chin \\ St George Cancer Care Centre, Kogarah, Australia
}

See next page for additional authors

Follow this and additional works at: https://ro.uow.edu.au/engpapers

Part of the Engineering Commons

https://ro.uow.edu.au/engpapers/621

\section{Recommended Citation}

Cutajar, Dean; Lerch, Michael L.; Takacs, George J.; Lee, Bong Soo; Chin, Y; Bucci, J; Zaider, M; Zelefsky, M; Yamada, J.; Cohen, Gil'ad; Perevertaylo, V L; and Rosenfeld, Anatoly B.: Urethral alarm probe for permanent prostate implants 2008, 455-457.

https://ro.uow.edu.au/engpapers/621

Research Online is the open access institutional repository for the University of Wollongong. For further information contact the UOW Library: research-pubs@uow.edu.au 


\section{Authors}

Dean Cutajar, Michael L. Lerch, George J. Takacs, Bong Soo Lee, Y Chin, J Bucci, M Zaider, M Zelefsky, J. Yamada, Gil'ad Cohen, V L Perevertaylo, and Anatoly B. Rosenfeld 


\title{
Urethral Alarm Probe for Permanent Prostate Implants
}

\author{
D.CUTAJAR ${ }^{1}$, M.LERCH ${ }^{1}$, G.TAKACS ${ }^{1}$, B.LEE ${ }^{2 *}$, Y.S.CHIN ${ }^{3}$, J.BUCCI ${ }^{3}$, M. ZAIDER ${ }^{4}$, M. ZELEFSKY ${ }^{4}$, J.YAMADA ${ }^{4}$, \\ G.N. COHEN ${ }^{4}$, V.L.PEREVERTAYLO ${ }^{5}$ and A.B. ROSENFELD ${ }^{1 *}$ \\ ${ }^{I}$ Centre for Medical Radiation Physics, University of Wollongong, Australia \\ ${ }^{2}$ Department of Biomedical Engineering, College of Biomedical \& Health Science, Konkuk University, South Korea \\ ${ }^{3}$ St George Cancer Care Centre, Kogarah, Australia \\ ${ }^{4}$ Memorial Sloan Kettering Cancer Center, New York, USA \\ ${ }^{5}$ SPA BIT, Ukraine
}

\begin{abstract}
We have developed a urethral dosimetry system for real time dose verification along the urethra during permanent implant prostate brachytherapy. The urethral alarm probe uses "spectroscopic dosimetry" to calculate the dose rate along the urethra in real time. The application of spectroscopic dosimetry for the urethral alarm probe was verified using Monte Carlo calculations. In phantom depth dose measurements as well as isotropy measurements were performed to verify the usefulness of the urethra alarm probe as an in vivo real time dosimeter.
\end{abstract}

\section{KEYWORDS: permanent implant, brachytherapy, prostate, real time, spectroscopic dosimetry, Monte Carlo}

\section{Introduction}

Permanent prostate implants are a common treatment modality for early stage prostate cancer. Reducing the risk of complications, whilst at the same time maintaining good dosimetric coverage of the tumor, is a major concern in prostate brachytherapy. We have developed a probe which measures in real time the dose delivered along the urethra and may be used by the physicians during seed implantation to monitor for excessive doses. In vivo dosimetry is commonly performed with miniature radiation detectors such as MOSFETs or diodes ${ }^{1)}$. The main disadvantages of such systems are energy dependence and low sensitivity. The urethral alarm probe circumvents these problems by measuring the energy spectrum of the treatment radiation field. The dose rate at the point of measurement is proportional to the magnitude of the measured photopeaks. The urethral alarm probe consists of a silicon mini-detector connected to a shaping amplifier and discriminator, located inside a cable small enough to be inserted within a urethral catheter. A portable data acquisition system provides real time dose calculations and extrapolated total treatment doses. The following reports on Monte Carlo calculations and physical experiments to confirm the suitability of spectroscopic dosimetry as a tool for low dose rate in vivo measurements.

\section{Methodology}

\section{Monte Carlo Simulations}

EGSnrc v4 ${ }^{2)}$ was used for the following Monte Carlo simulations. The user code DOSRZnrc was used to score doses in a water phantom whereas the user code FLURZnrc was used to score particle fluence in a water phantom.

${ }^{*}$ Corresponding Author, Tel No: +61-2-4221-4574, Fax No: +612-4221-4954, E-Mail: anatoly@uow.edu.au

${ }^{* *} \mathrm{~B}$. Lee is currently a visiting fellow at CMRP on sabbatical
An iodine 125 based brachytherapy seed, model 6711 from Amersham Health, was modeled in a large liquid water phantom. The dose deposited in the phantom was recorded at $5 \mathrm{~mm}$ intervals up to $5 \mathrm{~cm}$ from the seed along the transverse axis and normalized to 1 at $1 \mathrm{~cm}$. The particle fluence was also recorded at $5 \mathrm{~mm}$ intervals up to $5 \mathrm{~cm}$ from the seed long the transverse axis. The number of events in the photopeaks were counted for each of the spectra and normalized to 1 at $1 \mathrm{~cm}$, to simulate the application of spectroscopic dosimetry, calibrated at a distance of $1 \mathrm{~cm}$ from the seed. The two depthdose curves were plotted to compare the DOSRZnrc predicted dose and the spectroscopic dosimetry predicted dose.

\section{Phantom Measurements}

1) Depth dose measurements

An iodine 125 based seed was placed inside a gel phantom. The urethral alarm probe was used to measure the extrapolated treatment dose at various distances from the seed along the transverse axis. These doses were plotted in comparison with TG43 (3) calculated doses.

\section{2) Isotropy measurements}

An iodine 125 based seed was placed inside a gel phantom. The urethral probe was placed $1 \mathrm{~cm}$ from the seed on the transverse axis of the seed. The probe was rotated $360^{\circ}$ with measurement taken every $30^{\circ}$ to measure the azimuth isotropy of the detector. The probe was then moved parallel to the seed with measurements taken every $5 \mathrm{~mm}$. Each step of $5 \mathrm{~mm}$ increased the polar angle of measurement, but also increased the source to detector distance. The measured dose vs. expected dose was plotted to investigate the polar isotropy of the detector.

\section{Results}

\section{Monte Carlo Simulations}


The application of spectroscopic dosimetry has been simulated using FLURZnrc. Fig. 1 shows the comparison of spectra measured at $0.5 \mathrm{~cm}$ and $5 \mathrm{~cm}$ from an iodine 125 based seed. It can be seen from Fig. 1 that the shape of the spectrum does not change significantly with distance, although the fluence has greatly decreased. This indicates that spectroscopic dosimetry may be viable over a large range of depths (up to $5 \mathrm{~cm}$ from sources).

a)

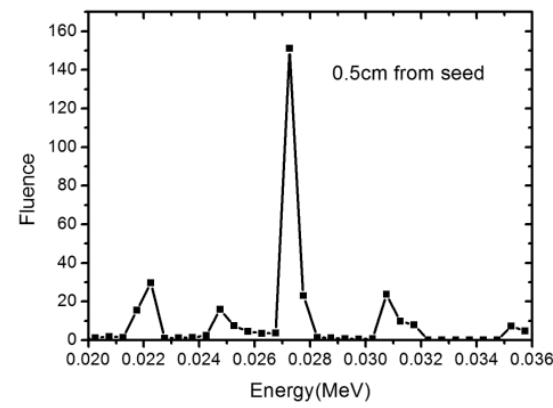

b)

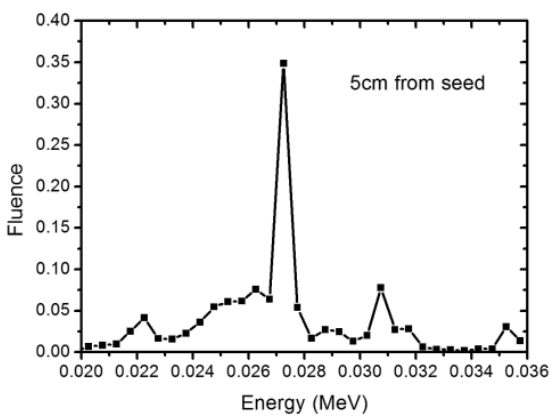

Fig.1 Spectra at depths of a) $0.5 \mathrm{~cm}$ and b) $5 \mathrm{~cm}$ from an iodine 125 seed.

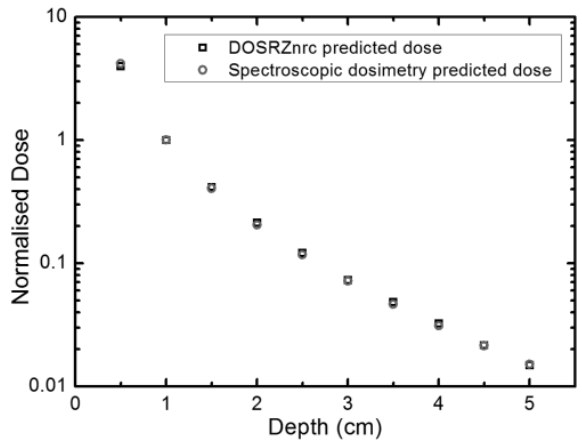

Fig. 2 Spectroscopic dosimetry predicted dose and DOSRZnrc predicted dose vs. depth

Fig. 2 shows the depth dose curves for both the spectroscopic dosimetry predicted doses and calculated doses, up to $5 \mathrm{~cm}$ from an iodine 125 based seed. Spectroscopic dosimetry has predicted the dose to within $2 \%$ of the calculated dose for each point of measurement.

\section{Phantom Measurements}

The measured spectrum of an iodine 125 based seed in free air is shown in Fig. 3. Several peaks are well resolved, indicating the urethral alarm probe is adequate for performing spectroscopy based dose calculations.

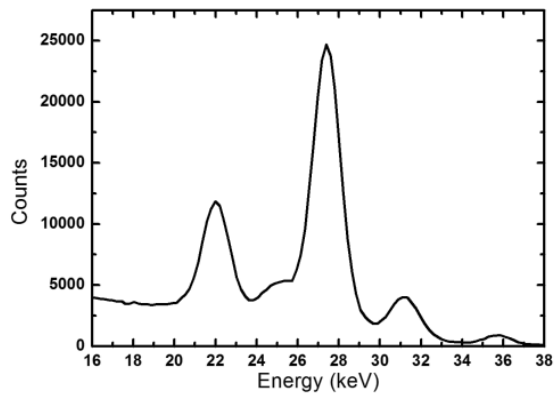

Fig. 3 Iodine 125 based seed spectrum as measured by the urethral alarm probe at a distance of $1 \mathrm{~cm}$ in free air.

Depth dose curves for an iodine 125 based seed in a gel phantom as measured by the urethral alarm probe and as calculated by TG43 are shown in Fig. 4. The urethral alarm probe has measured the doses to within $5 \%$ of the expected doses.

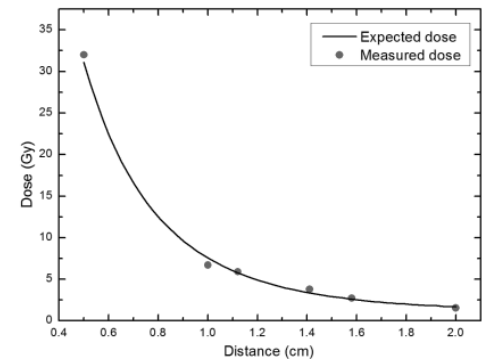

Fig. 4 Depth dose curve from an Iodine 125 based seed in a gel phantom as measured by the urethral alarm probe and calculated using TG433).

The azimuthal isotropy of the urethral alarm probe is represented in Fig. 5. The urethral alarm probe has an isotropy within $4 \%$ of the mean response for $360^{\circ}$ about the detector azimuth.

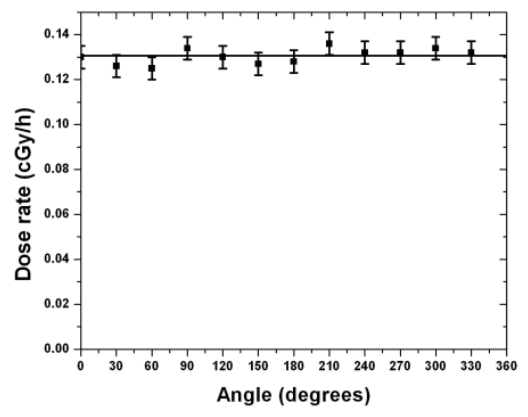

Fig. 5 Azimuthal isotropy of the urethral alarm probe

The polar isotropy of the urethra alarm probe is represented in Fig. 6. The decrease in dose with an increase of angle between transverse axis of the seed and direction from the seed center to the detector is due to the increasing source to detector distance. The measured doses were within $5 \%$ of the calculated doses. The urethral alarm probe exhibits a polar isotropy to within $5 \%$ for angles up to $80^{\circ}$ from the polar axis. 


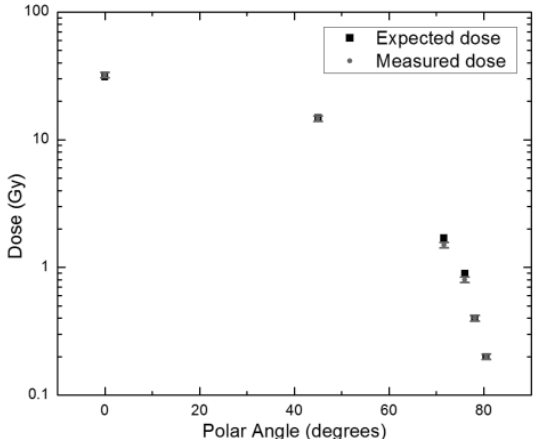

Fig. 6 Polar isotropy of the urethral alarm probe

\section{Conclusion}

The urethral alarm probe has been developed to provide real time dosimetry for permanent implant prostate brachytherapy. Monte Carlo calculations have shown spectroscopic dosimetry to be accurate to within $2 \%$ up to $5 \mathrm{~cm}$ from low energy $\mathrm{x}$-ray sources with distinct emission spectra. The urethra alarm probe uses spectroscopic dosimetry to measure low dose rates to an accuracy of within
$5 \%$ of calculated doses, up to $5 \mathrm{~cm}$ from sources, and for all angles of incidence about the detector (for both azimuth and polar angles).

The urethral alarm probe demonstrates the ability for real time in vivo dose measurements using spectroscopic dosimetry. The patented urethral alarm probe will be a very useful tool in clinical dose verification both during seed implantation and post implant.

\section{References}

1) A.B. Rosenfeld, D.L. Cutajar, M.L.F. Lerch, G.J. Takacs, J. Brady, T.Braddock, V.L. Perevertaylo, J. Bucci, J. Kearsley, Zaider M, Zelefsky, In vivo dosimetry and seed localization in prostate brachytherapy with permanent implants. IEEE Trans. Nucl. Science, 51: 3013-3018 (2004).

2) I. Kawrakow and D. W. O. Rogers, "The EGSnrc code system," NRC, Ottawa, ON, Canada, NRC Rep. PIRS-701, (2000)

3) R. Nath, L. L. Anderson, G. Luxton, K. A. Weaver, J. F. Williamson, A. S. Meigooni, "Dosimetry of interstitial brachytherapy sources: Recommendations of the AAPM Radiation Therapy Committee Task Group No. 43," Med Phys, 22 (2), Feb, pp 209-234 (1995) 